\title{
Analise florística do componente arbóreo urbano da cidade de Não-me-toque, RS, Brasil
}

Floristic analysis of the urban arbor component of Não-me-toque city, RS, Brazil

Análisis árbol de componentes florísticos ciudad urbana Não me toque, RS, Brasil

\author{
Evanisa Fátima Reginato Quevedo Melo \\ Professora Doutora, UPF, Brasil \\ evanisa@upf.br
}

Adele Stein Khun

Professora Mestre, UPF, Brasil. adele.nmt@gmail.comr

Ricardo Henryque Reginato Quevedo Melo

Professor Mestre, IMED/UFRGS, Brasil. ricardohquevedo@gmail.com 


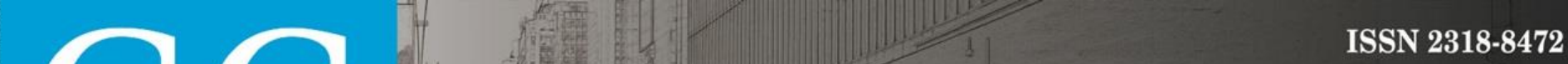

\section{Revista Nacional de}

Gerenciamento de Cidades

National Journal of Cities Management

\section{RESUMO}

A arborização urbana é de fundamental importância para o bem-estar da população citadina. O objetivo deste trabalho foi descrever de forma qualitativa e quantitativa a arborização de uma área previamente delimitada no Centro, bem como dos bairros Boa Vista e Jardim, do município de Não-Me-Toque, Estado do Rio Grande do Sul, Brasil e fornecer subsídios para implantação de políticas públicas por parte da administração municipal contribuindo para o planejamento ambiental. Foram amostrados 1255 indivíduos, distribuídos em 94 espécies e 40 famílias. Em média $62,23 \%$ da vegetação apresentam problemas fitossanitários, principalmente infestação por cupins. Em torno de $50 \%$ das plantas amostradas estão plantadas a menos de cinco metros umas das outras. As alturas das árvores variaram de um a vinte e dois metros, 1360 plantas $(77,2 \%)$ possuem altura inferior a cinco metros, das 401 plantas restantes $178(44,4 \%)$ estão sob a rede elétrica. Recomenda-se evitar o plantio de Lagerstroemia indica (extremosa) e fazer a adequação dos espaçamentos entre árvores e destas até a esquina. 0 Conhecimento da vegetação urbana possibilita estabelecer diretrizes de planejamento ambiental e incentivar o plantio das espécies arbóreas nativas para valorizar o entorno paisagístico natural da cidade contribuindo na sustentabilidade e ambiência.

PALAVRAS-CHAVE: Vegetação urbana, Planejamento urbano, Paisagismo. 


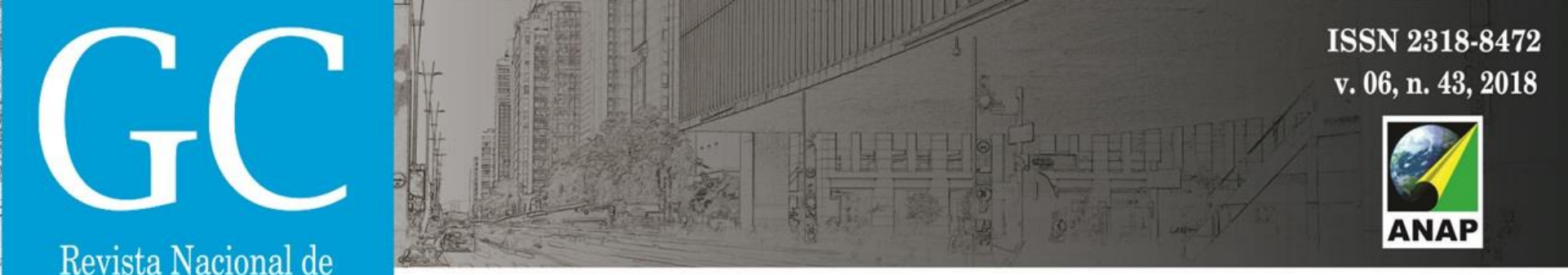

Revista Nacional de

Gerenciamento de Cidades

\section{INTRODUÇãO}

A urbanização causa impacto especialmente na cobertura do solo, na concentração de gases contaminantes, altera o micro-clima, afeta a saúde física e mental da população (ROMERO, 2001), assim o desenho urbano dos espaços livres está intimamente ligado à vida das cidades pelas suas ruas, praças e parques que caracterizam a paisagem urbana e neste contexto a arborização urbana promove o reencontro do homem com a natureza, desenvolvendo atividades em diferentes ritmos e escalas da vida cotidiana (KLIASS; MAGNOLI, 2006).

O município de Não-Me-Toque, assim como muitos outros, possui vias públicas e praças com arborização já constituída. No entanto, a gestão pública desconhece a ampla variedade de espécies que compõe a vegetação arbórea do município o que é fundamental para intervir com critérios e subsídios técnicos para as tomadas de decisões de planejamento e projeto.

A arborização urbana vem se tornando mais relevante nas urbes, pelo fato da população estar se tornando cada vez mais urbana. É imprescindível fazer um levantamento e inventariar a vegetação arbórea do município para um adequado planejamento municipal. Assim conhecer o porte das árvores, distribuição e localização se torna tarefa fundamental no planejamento urbano, uma vez que as cidades estão sofrendo com um alto grau de urbanização e com intensas áreas impermeabilizadas, que pode acarretar ao ambiente urbano grandes superfícies acumuladoras e refletoras de calor, alta concentração de poluição e mudança na biodiversidade (FERRAZ, 2012).

A vegetação arbórea tem importantes funções, tais como reduzir a intensidade de ruídos, melhorar o microclima, reduzir a poluição, além do seu valor estético por "quebrar a artificialidade do meio". Pelas características já citadas e outras como fornecer alimento e abrigo à fauna silvestre e proporcionar sombreamento e lazer para o ser humano, a arborização das cidades é um fator determinante da salubridade ambiental (SILVA FILHO et al.2002; DANTAS; SOUZA, 2004 apud MELO; LIRA FILHO; RODOLFO, 2007; BONAMETTI, 2008, MELO e ROMANINI, 2008; MELO e SEVERO, 2010).

A arborização das vias públicas traz muitos benefícios para a comunidade local, mas para que se obtenha sucesso neste processo há a necessidade de se fazer um planejamento prévio. Para realizar esta tarefa de maneira adequada e eficaz, é necessário levar em consideração vários elementos já existentes nestes locais como fiação elétrica e de telecomunicação, encanamento de água e esgoto, bocas de lobo, edificações próximas, trânsito de pedestres e veículos. Ainda é preciso conhecer as plantas que se pretende utilizar, pois estas não podem possuir espinhos no tronco, frutos muitos grandes, princípios ativos tóxicos (alergênicos); saber o porte e o hábito da árvore (enraizamento, dimensão da copa, etc). A falta de um planejamento prévio causa muitos transtornos, como o entupimento de calhas e bocas-de-lobo, obstrução das vias de trânsito para pedestres e veículos, interrupção no fornecimento de energia elétrica e acidentes envolvendo pedestres, veículos ou edificações (SILVA FILHO et al., 2002; SILVA et al., 2002, PIRES et al, 2010, FERRAZ, 2012). 


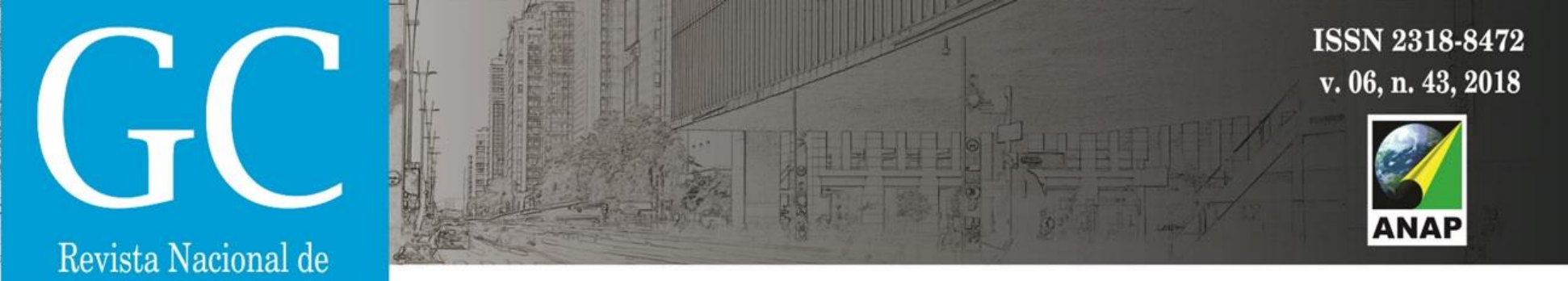

Gerenciamento de Cidades

National Journal of Cities Management

Este trabalho objetivou descrever de forma qualitativa e quantitativa a arborização de uma área previamente delimitada no Centro, bem como dos bairros Boa Vista e Jardim, do município de Não-Me-Toque, Estado do Rio Grande do Sul, e fornecer subsídios para implantação de políticas públicas por parte da administração municipal.

\section{MATERIAL E MÉTODOS}

O estudo foi realizado no município de Não-Me-Toque, Jardim do Alto Jacuí, localizado no Planalto Médio do Rio Grande do Sul, na microrregião do Alto Jacuí, com uma área territorial de $365,5 \mathrm{Km}^{2}$ e uma população urbana de 13.494 habitantes, com uma densidade demográfica de 41,8 habitantes $/ \mathrm{km} 2$. Localiza-se a $512 \mathrm{~m}$ de altitude em relação ao nível do mar, na latitude 28 27' 33" S e longitude 52 49' 15" O.

O Centro da cidade caracteriza-se como zona residencial e comercial, deste foi inventariada uma área amostral que compreende a Avenida Alto Jacuí, a Avenida Doutor Waldomiro Graeff, a Rua Coronel Alberto Schmitt e a Praça-matriz Doutor Otto Sthall. Os bairros Boa Vista e Jardim são essencialmente residenciais e tiveram todas as suas ruas inventariadas, num total de 22 ruas nos dois bairros (Figura 1).

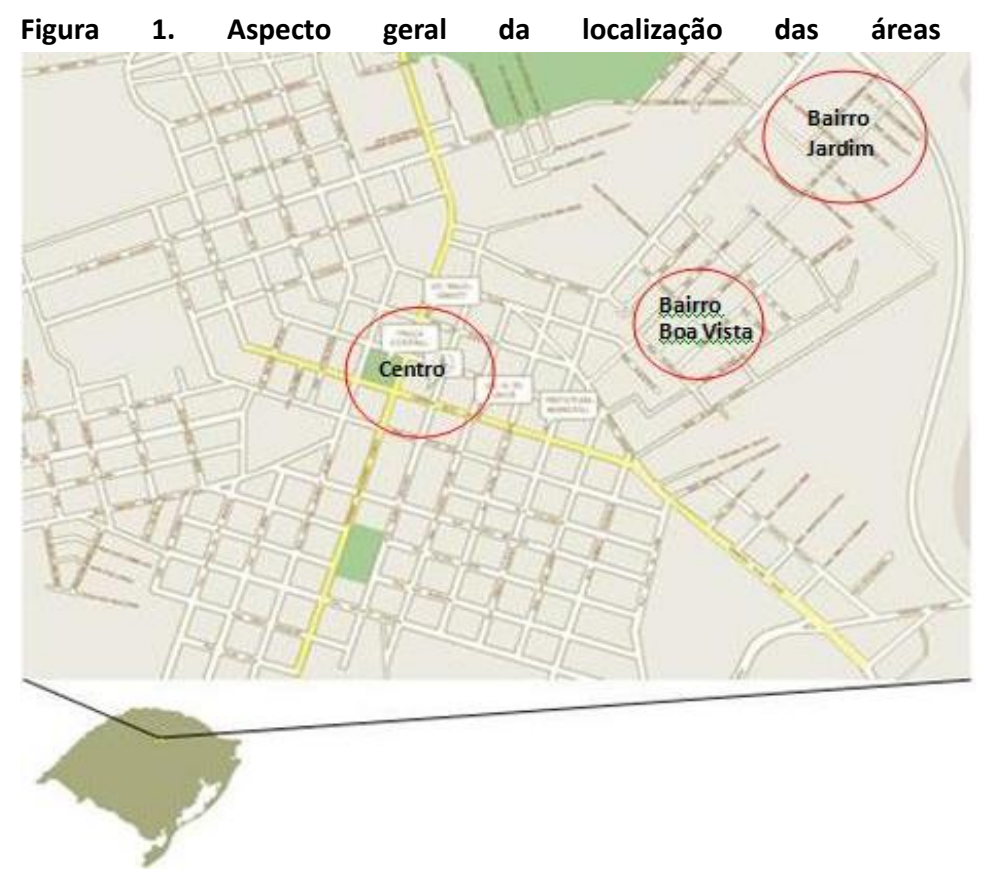

amostradas, Não-Me-Toque, RS. 


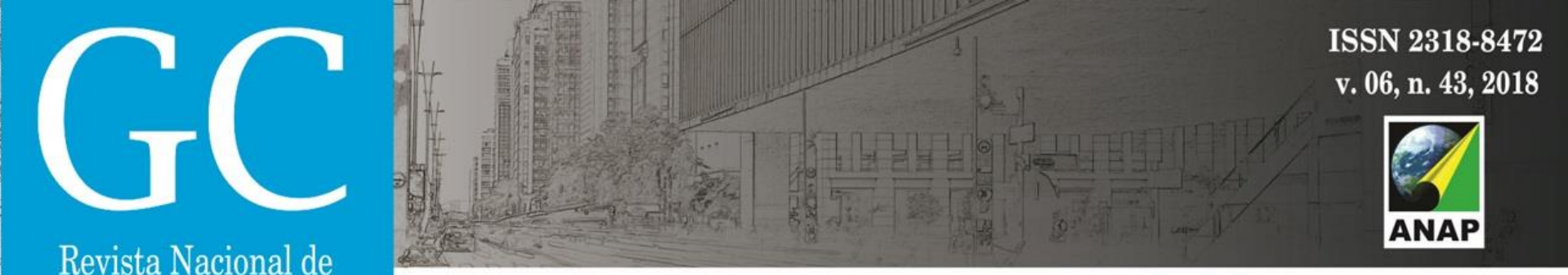

Revista Nacional de Gerenciamento de Cidades

Foi realizado levantamento do tipo censo, com caráter quali-quantitativo, na constituição do inventário.

O censo foi realizado no período de setembro de 2008 a julho de 2010, conforme ficha elaborada para o cadastro da arborização urbana, contendo os seguintes itens para os logradouros: número da árvore a ser inventariada; número da quadra; data da coleta; nome da rua; número da casa ou estabelecimento do local (para localização da planta); lado da rua; nome da espécie; altura da árvore; CAP (circunferência à altura do peito); diâmetro da copa (longitudinal ao meio fio); presença de rede elétrica aérea (ramal, telefonia, baixa tensão e alta tensão); espaçamento entre indivíduos e do primeiro e última árvore da quadra até a esquina, considerando sete metros o mínimo aceitável para não interferir no trânsito. Na ficha elaborada para a praça foram considerados os itens: número da árvore a ser inventariada; data da coleta; nome da espécie; altura da árvore; CAP (circunferência à altura do peito); diâmetro da copa; estado fitossanitário, usando a mesma classificação dos logradouros; e ponto no GPS. O material de campo utilizado foi fita métrica centimetrada de $8 \mathrm{~m}$, trena centimetrada de $50 \mathrm{~m}$, GPS, pranchetas, mapa oficial do município, fichas e canetas. Os dados obtidos em campo foram plotados em tabelas do cadastro de arborização urbana para posterior análise.

\section{RESULTADOS E DISCUSSÃO}

A arborização de praças são consideradas dentro das bases téorico-metodologica com importantes instrumentos para a promoção da qualidade de vida urbana. Assim como a vegetação das ruas requer, para a efetivação dos benefícios esperados, que seja planejada e mantida de forma sustentável, assim foram divididas em setores e temas os resultados para a discussão.

\section{Praça Dr. Otto Sthall}

Na praça foram amostrados 217 indivíduos, de 48 espécies, distribuídas em 25 famílias. As espécies mais abundantes são Syagrus romanzoffiana com 29 indivíduos $(13,4 \%)$ e Jacaranda mimosaeifolia com 22 espécimes (10,1\%). Nenhuma das espécies ultrapassou os $15 \%$ do total de indivíduos, o máximo aceitável em uma mesma cidade, parâmetro citado por Ruschel e Leite (2002), conforme as recomendações da ISA (International Society of Arboriculture).

Com relação ao estado fitossanitário, 152 plantas, $70 \%$ do total, encontram-se classificadas nas categorias 1 e 2, que indicam um bom estado de conservação da arborização da praça. Com relação ao porte, a maior parte das árvores encontra-se com baixo (até $9,5 \mathrm{~m}$ de altura) e médio (entre $9,5 \mathrm{~m}$ e $17 \mathrm{~m}$ ) portes, $82,5 \%$ do total.

Considerando que a praça é um espaço público de importância para a comunidade, deve garantir e transmitir segurança, conforto e lazer para seus frequentadores, visitantes e 
moradores do local, permitindo o convívio social, prática de esportes e atividades de lazer ao ar livre, servindo de palco para manifestações coletivas e apresentando grande diversidade de espécies arbóreas, concordando com o encontrado em análises de cidades de médio porte (MELO; ROMANINI, 2008).

\section{Riqueza e freqüência relativa das espécies}

Nas ruas inventariadas no Centro foram amostradas 691 plantas, distribuídas em 26 famílias, 50 espécies e 29 espécimes não identificados. As espécies mais abundantes foram Handroanthus chrysotricha (ipê-amarelo) e Lagerstroemia indica (extremosa), que correspondem, respectivamente, a $33,4 \%$ e $17,5 \%$ do total. A distribuição entre espécies exóticas à flora do Rio Grande do Sul e nativas é bastante equilibrada, 56,3\% das plantas são nativas (Figura 3).

Foram catalogadas 595 plantas no bairro Jardim, distribuídas em 32 famílias, 66 espécies e 19 indivíduos não identificados. A espécie mais abundante é Ligustrum sp. (ligustro), com 33,8\% do total de exemplares. A relação entre espécies nativas e exóticas é de 1:5, as espécies exóticas perfazem um total de $82,9 \%$ do total amostrado neste bairro, conforme Figura 3 .

No bairro Boa Vista foram inventariadas 475 plantas, distribuídas em 22 famílias, 41 espécies e 14 exemplares não identificados. A espécie mais abundante é Lagerstroemia indica (extremosa), 17,5\% das plantas encontradas no bairro. Do total de plantas, 393 são exóticas, o que corresponde a $82,6 \%$ do total.

Figura 3. Aspecto geral da arborização na praça Dr. Otto Sthall, Não-me-Toque, RS, 2010.

Proproção entre espécies nativas e exóticas
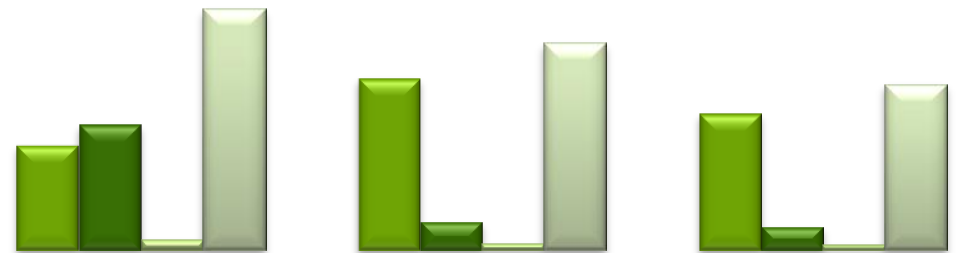

口Exóticas

- Nativas

$\square$ Não identificadas

$\square$ Total

Bairros 


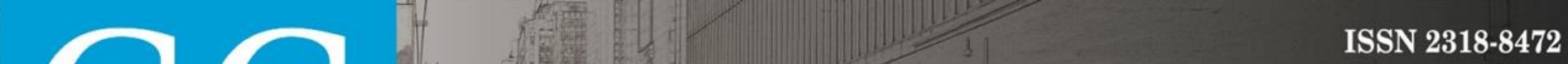

Em todos os bairros estudados foi constatada uma freqüência de ocorrência desuniforme e grande número de espécies exóticas, concordando com resulatados de Ferraz (2012) para a cidade de Registro-SP concluindo que a arborização urbana não foi planejada, uma vez que a cidade possui um número baixo de espécies nativas e um número muito alto de exóticas.

Verificou-se que há predominância de alguma espécie, acima do máximo recomendado pela ISA, sendo que em dois deles uma destas espécies é a Lagerstroemia indica (extremosa), demonstrando que essa foi largamente plantada na cidade.

Deve-se utilizar, no mínimo, de sete a dez diferentes espécies para compor a arborização de uma cidade, sendo um número entre 10 e 20 bastante recomendável (MILANO; DALCIN, 2000). Como a maioria das espécies se repete nos bairros, foi encontrado 94 diferentes espécies no total. Esta variedade é boa para controle de pragas e doenças, mas já é uma variedade um pouco alta para se efetuar a manutenção destas, já que cada espécie tem um ciclo de vida próprio.

Toscan et. al. (2010), citam que a maioria das plantas arbóreas usadas na arborização urbana das cidades é de espécies exóticas, apesar de a flora nativa contar com espécies de grande beleza paisagística. Assim o conhecimento da composição arbórea do município permite aos gestores públicos incluir nas diretrizes de planejamento urbano, medidas que possam beneficiar a arborização das áreas públicas bem como proporcionar melhores condições ecológicas, ambientais, sustentáveis e de qualidade de vida aos munícipes (MELO e SEVERO, 2010).

\section{Espaçamento entre árvores e até a esquina}

Os espaçamentos entre árvores foram adequados (mais de cinco metros) em $44,1 \%$ dos casos no Centro, mas o percentual de árvores plantadas a menos de cinco metros uma da outra é alto, correspondendo a $41,1 \%$ do total. Em relação à esquina, das 106 plantas que foram encontradas no final da quadra, $51,9 \%$ se encontram a menos de sete metros da esquina, que é o mínimo estabelecido pela legislação municipal.

No bairro Jardim foram encontradas 320 plantas $(53,8 \%)$ com espaçamento de até cinco metros de distância entre elas, o que é muito pouco. Já a distância mínima até a esquina (ao menos sete $\mathrm{m}$ ) é respeitada em 76,6\% dos casos, conforme Tabela 1.

A metade dos vegetais do bairro Boa Vista $(49,5 \%)$ possui espaçamento de até cinco metros entre si. A distância até a esquina respeita os sete metros em $55,4 \%$ dos casos.

Em torno de $50 \%$ das plantas que compõem a arborização urbana do município está a menos de cinco metros uma da outra. Segundo Sanchotene (2000) o espaçamento mínimo entre árvores é de cinco metros, desta forma, em torno da metade da arborização do município precisa ser adequada. 


\section{Classes de altura e rede elétrica aérea}

Os portes das árvores variam de 1 a 22 metros de altura no Centro, sendo que 413 (59,8\%) vegetais possuem até cinco metros de altura, $245(39,4 \%)$ possuem altura entre 5 e 15 metros e $41,9 \%$ destas últimas estão sob fiação elétrica.

A vegetação do bairro Jardim varia de um até vinte metros de altura, sendo que $522(87,7 \%)$ árvores possuem no máximo cinco metros. As outras 73 plantas possuem entre cinco e vinte metros de altura, sendo que deste total $58,9 \%$ estão situados sob a rede létrica, conforme Tabela 1.

No bairro Boa Vista foram encontradas plantas com altura variando de um a vinte metros, sendo que $425(89,5 \%)$ tem altura inferior a cinco metros. Das 51 árvores restantes, 21 (43,8\%) estão sob a rede elétrica.

Tabela 1. Porte das árvores e presença/ausência de fiação elétrica, por bairro.

\begin{tabular}{|c|c|c|c|c|c|c|c|c|c|c|c|c|}
\hline \multicolumn{13}{|c|}{ Porte/Fiação Elétrica (Size/Wiring electrical) } \\
\hline \multicolumn{13}{|c|}{ Centro (Downtown) } \\
\hline & Até $5 \mathrm{~m}$ & $\mathrm{P}^{*}$ & $A^{* *}$ & 5 a $10 m$ & $\mathrm{P}^{*}$ & $A^{* *}$ & 10 a $15 \mathrm{~m}$ & $\mathrm{P}^{*}$ & $A^{* *}$ & Mais de $15 \mathrm{~m}$ & $\mathrm{P}^{*}$ & $A^{* *}$ \\
\hline Total & 413 & 162 & 251 & 246 & 109 & 137 & 26 & 5 & 21 & 6 & 0 & 6 \\
\hline$\%$ & 59,8 & 39,2 & 60,8 & 35,6 & 44,3 & 55,7 & 3,8 & 19,2 & 80,8 & 0,9 & 0,0 & 100,0 \\
\hline \multicolumn{13}{|c|}{ Bairro Jardim (Neighborhood Jardim) } \\
\hline & Até $5 \mathrm{~m}$ & $\mathrm{P}^{*}$ & $A^{* *}$ & 5 a $10 m$ & $\mathrm{P}^{*}$ & $A^{* *}$ & 10 a $15 m$ & $\mathrm{P}^{*}$ & $A^{* *}$ & Mais de $15 \mathrm{~m}$ & $\mathrm{P}^{*}$ & $A^{* *}$ \\
\hline Total & 522 & 255 & 267 & 65 & 39 & 26 & 7 & 3 & 4 & 1 & 1 & 0 \\
\hline$\%$ & 87,7 & 48,9 & 51,1 & 10,9 & 60,0 & 40,0 & 1,2 & 42,9 & 57,1 & 0,2 & 100,0 & 0,0 \\
\hline \multicolumn{13}{|c|}{ Bairro Boa Vista (Neighborhood Boa Vista) } \\
\hline & Até $5 \mathrm{~m}$ & $\mathrm{P}^{*}$ & $A^{* *}$ & 5 a $10 m$ & $\mathrm{P}^{*}$ & $A^{* *}$ & 10 a $15 m$ & $\mathrm{P}^{*}$ & $A^{* *}$ & Mais de $15 \mathrm{~m}$ & $\mathrm{P}^{*}$ & $A^{* *}$ \\
\hline Total & 425 & 234 & 191 & 48 & 21 & 27 & 1 & 0 & 1 & 2 & 0 & 2 \\
\hline$\%$ & 89,5 & 55,1 & 44,9 & 10,1 & 43,8 & 56,3 & 0,2 & 0,0 & 100,0 & 0,4 & 0,0 & 100,0 \\
\hline
\end{tabular}

Legenda: * Fiação elétrica presente; ** Fiação elétrica ausente.

O município de Não-Me-Toque possui rede elétrica instalada de forma convencional (aérea), com os fios de baixa tensão colocados a partir de cinco metros do solo. Desta forma, as 


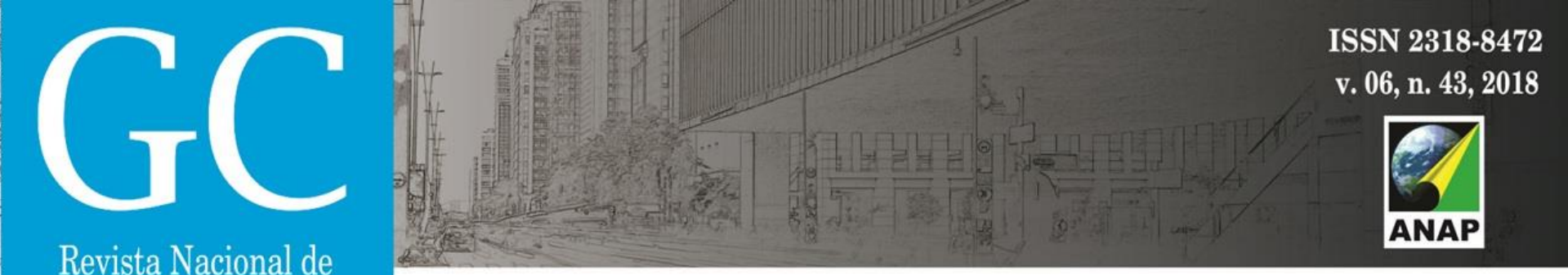

Gerenciamento de Cidades

árvores com altura acima da citada possuem conflitos com a rede, tendo que sofrer podas de adequação. Em muitos dos casos foi constatado o uso de poda drástica para tal fim, um dos fatores que pode ter contribuído para o estado fitossanitário verificado, onde em média $62,2 \%$ das plantas amostradas no município estavam com problemas. Situação semelhante foi encontrada por Schuch e Mello Filho (2006) em São Pedro do Sul - RS, que sugeriram reavaliar as condições de plantio do ipê-amarelo, ligustro e aroeira-vermelha (Schinus terebinthifolius) os quais apresentaram maior incidência de problemas.

Rocha et al. (2004) encontraram situação semelhante em Nova Iguaçu/SP, tendo 55\% das plantas do centro com altura inferior a seis metros e $37,3 \%$ das árvores do bairro Rancho Novo com altura de até 3,5 metros. Deve-se levar em consideração que das árvores com alturas inferiores a cinco metros grande parte são juvenis, não tendo atingido os três metros de altura ainda. Desta forma, parte desta vegetação ainda poderá apresentar conflitos futuros com a rede elétrica, e, por consequência, poderão ter problemas fitossanitários

\section{CONCLUSÕES}

O plantio de Lagerstroemia indica (extremosa) deve ser evitado, para diminuir a homogeneidade da vegetação na cidade.

É preciso incentivar o plantio de mais espécies nativas para valorizar o entorno paisagístico natural da cidade.

Com relação à fiação elétrica, a RGE está trocando os fios antigos por novos que possuem isolamento, mas será necessário realizar manutenção por alguns anos para adequar a vegetação à rede.

Há a necessidade de adequação de grande parte da arborização, tanto para melhorar o espaçamento entre árvores, quanto para adequar as distâncias até a esquina que estão interferindo no trânsito.

O Conhecimento da vegetação urbana possibilita estabelecer diretrizes de planejamento ambiental e incentivar o plantio das espécies arbóreas nativas para valorizar o entorno paisagístico natural da cidade contribuindo na diversidade da paisagem, na sustentabilidade e ambiência.

\section{REFERÊNCIAS BIBLIOGRÁFICAS}

ALIER, J. M. Varieties of Environmentalism. London: Earthscan Publications Ltda, 1997.

ASSOCIAÇÃO BRASILEIRA DE NORMAS TÉCNICAS. NBR 5706. Coordenação Modular da Construção - Procedimento. Rio de Janeiro: ABNT, 1977.

BARBIERI, J. C. Desenvolvimento e meio ambiente: as estratégias de mudanças da agenda 21. 6.ed. Petrópolis: Vozes, 2003. p. 15-37. 
